\title{
Exchange Rate Movements, Foreign Direct Investment, and Domestic $\mathrm{R} \& \mathrm{D}$
}

\author{
Kun-Ming Chen ${ }^{1}$, Chia-Ching $\operatorname{Lin}^{2} \&$ Shu-Fei Yang ${ }^{3}$ \\ ${ }^{1}$ Department of International Business, National Chengchi University, Taipei, Taiwan \\ ${ }^{2}$ Department of International Business, National Taichung University of Science and Technology, Taiwan \\ ${ }^{3}$ Chung Hua Institute for Economic Research, Taiwan \\ Correspondence: Kun-Ming Chen, Professor, Department of International Business, National Chengchi University, \\ Taipei 11605, Taiwan. Tel: 886-2-2938-7515. E-mail: kchen@nccu.edu.tw
}

Received: October 14, 2014

Accepted: November 13, 2014

Online Published: January 4, 2015

doi:10.5430/rwe.v6n1p20

URL: http://dx.doi.org/10.5430/rwe.v6n1p20

The financial support from National Science Council of Taiwan (Grant No.: NSC 101-240-H-004-025) is gratefully acknowledged.

\begin{abstract}
This paper develops a game-theoretical model to investigate heterogeneous firms' entry mode choice of international expansion. The distinct feature of this paper is that exchange rate, R\&D competition, and intra-industry firm heterogeneity are incorporated into the theoretical framework. The possible impact of a firm's outward foreign direct investment (OFDI) on its R\&D spending and other non-OFDI firms' R\&D spending is also examined. Our analytical results indicate that, if host country has lower labor costs, when facing rising domestic labor costs or appreciation of home currency, a firm with lower productivity in production or R\&D activity will choose OFDI, whereas the firms with higher productivity will produce at home and export. In addition, our results demonstrate that the impact of OFDI on R\&D spending is ambiguous, depending on firm heterogeneity as well as the wage gap between home country and host country.
\end{abstract}

Keywords: exchange rate, firm heterogeneity, foreign direct investment, R\&D

\section{Introduction}

An increasing number of theoretical and empirical studies in international trade have incorporated firm heterogeneity into their analysis in recent years. This new literature was triggered by interesting empirical findings from micro datasets, such as Bernard and Jensen $(1995,1999)$. One of the striking features of the empirical evidence from those micro datasets is that exporters and importers represent just a tiny fraction of producers across many developed and developing countries. In addition, exporters and importers tend to be larger, more productive, more skill- and capital-intensive, and pay higher wages prior their entry into international markets than non-trading firms, which suggest self selection. Based on the empirical observation, several theoretical studies have provided new insights about the relationship between firm heterogeneity and participation in international markets, such as Melitz (2003), Bernard, et al. (2003), and Helpman, et al. (2004), among others. (Note 1)

The essential feature in the theoretical framework of this new literature is the combination of sunk costs of international expansion and heterogeneity in the underlying characteristics of firms. This combination can explain why not all firms export and why only those firms with higher productivity export. In addition, this combination can also explain the relationship between productivity differences among firms and their choice between exports and foreign direct investment. Helpman, et al. (2004), for instance, extending the models by Brainard $(1987,1993)$ which stresses trade-off between proximity and concentration, incorporate productivity heterogeneity into their analytical framework and show that the choice of entry modes into international markets could differ across firms within the same industry. The sunk costs of outward foreign direct investment (OFDI, hereafter) are usually thought to be higher than exports. However, the variable costs of foreign production are lower because of the trade costs incurred by exports. Helpman, et al. (2004) predict that only the most productive firms become multinationals; firms whose productivity falls in an intermediate range export and the least productive only sell domestically. 
Helpman, et al. (2004) assume that the purpose of establishing foreign production facilities is for market access, and all OFDI is horizontally driven. By contrast, Head and Ries (2003) demonstrate that when there are factor price differences between host countries and home country so that certain OFDI is of vertical type, the ordering of productivity distribution between multinationals and non-multinationals can be reversed. If the host country has cost advantage, for instance, the least productive firms might locate abroad whereas more productive ones produce at home. This can be attributed to the fact that low productivity firms have a greater incentive to pay the higher sunk costs of OFDI because they use more intensively the factor whose overseas price is low.

Regarding the relationship between firm heterogeneity and entry mode choice, the extant theoretical studies are still limited. In addition, there are two limitations in the previous literature. First, traditional theory of foreign direct investment (Dunning (1977)) indicates that a firm's ownership advantages, including R\&D capability, have important bearing on a firm's decision of international expansion strategies. Sanna-Randaccio $(1998,2000)$ among others develop theoretical model to show that there exist two-way linkages between a firm's OFDI and its R\&D. Lu (2007) also demonstrates that industry R\&D heterogeneity affects the choice between domestic R\&D investment and OFDI of a firm across industries. However, a firm's R\&D investment and its possible interaction with its choice of entry modes are still not incorporated into the extant theoretical models of international expansion strategies with firm heterogeneity. Second, recent studies show that, given the sharp fluctuation of exchange rates over time in many countries, exchange rate might have played an important role in a firm's international expansion strategy, particularly for the firms in the less developed countries in which capital markets are still relatively underdeveloped. However, exchange rate is not considered in most previous theoretical studies except for Hsu (2011), which shows that home currency appreciation raises the likelihood of OFDI. (Note 2)

To fill the gap in this literature, the purpose this paper is develops a game-theoretical model to investigate heterogeneous firms' choices over entry modes of foreign expansion. In contrast to previous studies, the distinct feature of this study is that exchange rate, R\&D competition, and intra-industry firm heterogeneity are incorporated into our theoretical framework. Following Chen and Hsu (2003), Tsai and Chiou (2007), and Chen and Yang (2013), we examine the case in which a firm's OFDI is to take advantage of low-cost labor and resources in host counties rather than market access or the circumvention of trade barriers.

The rest of the paper is organized as follows. In the next section, we first develop a basic theoretical framework to analyze the impact of a monopoly firm's OFDI in low-wage countries on its R\&D spending. Section 3 then extend our analysis to the case of an oligopolistic model with two identical firms. Section 4 subsequently examines the case of two heterogeneous firms. The final section summarizes our major findings and provides brief concluding remarks.

\section{The Basic Model: A Monopoly}

\subsection{The Model}

To incorporate exchange rate, R\&D competition and firm heterogeneity into an oligopolistic model might make our model too complex to obtain any analytical solution. In order to derive some analytical results for better understanding of the driving forces behind our theory, in this section, we start with a simple theoretical framework to analyze the interaction of a monopoly firm's entry mode decision and its relationship with its domestic R\&D spending, and then extend this basic model to cases with duopoly.

We assume that a monopoly firm which produces to serve a foreign market. It can choose to manufacture its product in its home country and exports the product to the foreign market. It can also relocate his production activity to the foreign country to serve the market. Assume that the firm initially produces at home. When the firm faces an increase of domestic labor cost, it can relocate its production to country with lower labor cost, which strategy can be referred as "moving out" strategy. Alternatively, it can choose to increase its R\&D spending in order to raise its productivity to reduce the adverse impact of an increase in wage rates, which strategy can be referred to as "moving up" strategy ( $\mathrm{Lu}(2007))$. In this section, we illustrate that the firm's OFDI does not necessarily negatively relate to its domestic R\&D spending. In other words, its moving-out strategy and moving-up strategy can be either substitutes or complements.

Suppose that a monopoly firm uses labor input only to manufacture its product in the home country or a foreign country to serve the foreign market. The firm can undertake $R \& D$ to reduce its production costs before it determines its production level. Let $I$ be the level of R\&D undertaken by the firm and let $c$ denote the firms marginal cost. As for the relationship between the firm's marginal cost, ${ }^{c}$, and its R\&D spending, the following functional form suggested by Chen and Yang (2013), is adopted: 


$$
c(w, I)=w_{j}(v-\theta I), j=h, f
$$

where $v$ is a constant and can be considered as the initial labor requirement per unit of output, and ${ }^{w_{j}}$ is the wage rate in the home country $(\mathrm{j}=\mathrm{h})$ or in the foreign country $(\mathrm{j}=\mathrm{f})$. The parameter $\theta$, with $0 \leq \theta \leq 1$, represents the productivity of a firm's R\&D activity.

Eq. (1) implies that a firm can reduce its marginal cost of production in two ways, either lowering its labor cost by moving out to a country with lower labor costs or increasing its R\&D spending. Consequently, there exists a substitution effect induced by investing in low-wage countries on the firm's domestic R\&D spending. In addition, it should be noted that Eq. (1) implies that the returns on a firm's R\&D investment is assumed to be higher if a firm faces a higher wage rate. This suggests that the above-mentioned negative impact of OFDI on R\&D will be higher if the gap of the wage rates between home and host countries is larger. The specification of the marginal cost function in this setting is different from most previous studies in which the return on a firm's R\&D investment is assumed to be independent of the wage rates.

It is assumed that the firm has two entry modes for serving the foreign market: exports or OFDI. There exist sunk costs of exporting, which are typically thought to include fixed costs of research into product compliance, distribution networks, advertising and so on. (Note 3) There also exists a unit cost associated with exporting activities such as transportation costs, $S$. The sunk costs and variable costs associated with exporting activities are assumed to be zero for simplicity. If the firm attempts to take advantage of low-wage labor in the host country and decides to start a new plant there, it will incur additional plant-specific sunk costs $G$, which are usually supposed to be higher than the sunk costs of exporting.

We consider a linear (inverse) demand function,

$$
p=\alpha-q
$$

where $p$ is the output price in terms of foreign currency, and $q$ denotes the output of the firm. When the firm chooses exports as its international expansion mode, its profits are given by:

$$
\pi_{h}=\left[R \cdot p(q)-w_{h}(v-\theta I)\right] q-\gamma \frac{I^{2}}{2}
$$

where $R$ is the exchange rate, and $\left(\gamma I^{2}\right) / 2$ is the cost of R\&D investment with $\gamma_{>0 \text {, which is inversely related }}$ to the cost effectiveness of the firm's R\&D investment. The specification of the cost of R\&D investment implies that there exists decreasing returns to R\&D activity. Exchange rate is expressed in units of home currency per unit of foreign currency.

By contrast, if the firm decides to set up a new plant in the foreign country instead of exporting, the firm's profits are then given by:

$$
\pi_{f}=\left[R \cdot p(q)-R \cdot w_{f}(v-\theta I)\right] q-\gamma \frac{I^{2}}{2}
$$

It is assumed that the firm faces a three-stage decision problem. In the first stage, the firm determines if it will serve the market via exports or FDI. In the second stage, given the entry mode of the firm, it chooses its R\&D spending level. In the third stage, given its R\&D spending level, the firm then chooses its output level. The model is solved by backward induction. That is, given the firm's entry mode and R\&D decision, the output decision of the firm is solved first. Then the firm's optimal R\&D level is derived. Finally, the choice of the firm's entry mode is determined.

\subsection{Comparative Statics}

\section{The Case of Export}

The quantity decision problem for the case of export is solved first. For simplicity, the parameters of $v$ and $\alpha$ are assumed to be 1 in this section. From the first-order condition of profit maximization, we obtain the firm's optimal 
quantity as follows: (Note 4)

$$
q^{*}=\frac{R-w_{h}(1-\theta I)}{2 R}
$$

Substituting Eq. (5) into Eq. (3), we then solve the second stage problem, the R\&D decision problem. From the first-order condition, we can solve for the optimal R\&D level as follows: (Note 5)

$$
I^{*}=\frac{A_{1} w_{h} \theta}{A_{2}}
$$

where $A_{1}=R-w_{h}$ and $A_{2}=2 R \gamma-w_{h}^{2} \theta^{2}$. To ensure a positive output or R\&D level, we assume that $R-w_{h} \geq 0$ (thus $A_{1} \geq 0$ ), and $A_{2} \geq 0$.

Substituting Eq. (6) into Eq. (5) and then Eq. (3), we can derive the optimal quantity and profits, respectively, as follows:

$$
\begin{gathered}
q^{*}=\frac{\gamma A_{1}}{A_{2}} \\
\pi^{*}=\frac{\gamma A_{1}^{2}}{2 A_{2}}
\end{gathered}
$$

Proposition 1: The optimal R\&D level of the monopoly firm is positively related to its productivity of a firm's R\&D activity and the exchange rate of the home country, but negatively related to its investment cost of R\&D spending. However, the relationship between wage rate and its optimal R\&D level is indeterminate.

Proof: Differentiating Eq. (6) with respect to $\theta, \gamma, R$ and ${ }^{w_{h}}$, we have

$$
\begin{gathered}
\frac{\partial I^{*}}{\partial \theta}=-\frac{w_{h} A_{1}\left(2 R \gamma+w_{h}^{2} \theta^{2}\right)}{A_{2}^{2}}>0 \\
\frac{\partial I^{*}}{\partial R}=\frac{w_{h}^{2} \theta A_{3}}{A_{2}^{2}}>0 \\
\frac{\partial I^{*}}{\partial \gamma}=-\frac{2 R w_{h} \theta A_{1}}{A_{2}^{2}}<0 \\
\frac{\partial I^{*}}{\partial w_{h}}=\frac{R \theta\left(2 \gamma A_{1}-w_{h} A_{3}\right)}{A_{2}^{2}}, \text { where } A_{3}=2 \gamma-w_{h} \theta^{2} .
\end{gathered}
$$

Since the relative magnitude of $A_{1}$ and $A_{3}$ is unknown, the sign of $\frac{\partial I^{*}}{\partial w_{h}}$ is indeterminate.

The economic intuition behind the results regarding the relationship between the optimal R\&D and $\theta, \gamma$, or $R$ is straightforward. All of these parameters will make R\&D activity more profitable. Note that the higher the productivity of a firm's $R \& D$ activity is, the higher the returns from $R \& D$ activity will be. The higher the exchange rate of the home country (that is, the depreciation of its currency) is, the higher the marginal revenue of the firm will be so as to increase the firm's output. (Note 6) In addition, the higher the output is, the lower the average cost of 
R\&D will be. This is referred to as "cost-spreading effect" (Cohen and Klepper, 1996a, 1996b), or "sales-increasing effect" (Petit and Sanna-Randaccio, 1998) in the literature.

As for wage rate, it has two opposite effects on the optimal level of R\&D so that the direction of its impact is ambiguous. On one hand, since we assume that the returns from a firm's R\&D investment is higher if the firm faces a higher wage rate, as a result, a higher wage rate tends to stimulate a firm's R\&D spending. On the other hand, a higher wage rate increases its marginal production cost so as to depress the firm's output, as shown in Eq. (5). This will increase its average cost of $R \& D$, and thus reduce its optimal $R \& D$ spending.

\section{The Case of OFDI}

Appling similar reasoning as the case of export, we can solve for the optimal output and R\&D level from maximizing Eq. (4) with respect to output or R\&D, respectively. Using the first-order conditions, we have: (Note 7)

$$
\begin{aligned}
q^{* *} & =\frac{1-w_{f}(1-\theta I)}{2} \\
I^{* *} & =\frac{R w_{f} \theta\left(1-w_{f}\right)}{2 \gamma-R w_{f}^{2} \theta^{2}}
\end{aligned}
$$

Substituting Eq. (10) into Eq. (9) and then Eq. (4), we obtain the optimal output and profit levels, respectively, as follows:

$$
\begin{gathered}
q^{* *}=\frac{\gamma\left(1-w_{f}\right)}{2 \gamma-R w_{f}^{2} \theta^{2}} \\
\pi^{* *}=\frac{R \gamma\left(1-w_{f}\right)^{2}}{2\left(2 \gamma-R w_{f}^{2} \theta^{2}\right)}
\end{gathered}
$$

Since solutions between these the case of export and OFDI are almost the same except for the differences in wage rates ( ${ }^{w_{h}}$ versus $R w_{f}$ ), the comparative statics analysis for this case is omitted.

\section{The Choice of Entry Mode}

We can solve the firm's first-stage decision problem through the comparison between $\pi^{* *}$ and $\pi^{*}$. If $\pi^{* *}-\pi^{*}-G>0$, then it is profitable for the firm to relocate its production to the foreign country. We assume that the wage rates in these two countries have a proportionate relationship: $R w_{f}=\lambda w_{h}, 0 \leq \lambda \leq 1$. Here, $\lambda$ represents the wag gap between these two countries. This specification implies that initially the foreign country tends to have a lower labor cost, and the higher the value of $\lambda$ is, the higher the relative wage rate (in terms of the same currency) of the foreign country will be. Eqs. (10), (11) and (12) can be rewritten as follows:

$$
\begin{gathered}
I^{* *}=\frac{w_{h} \theta \lambda \tilde{A}_{1}}{\tilde{A}_{2}} \\
q^{* *}=\frac{\gamma \tilde{A}_{1}}{\tilde{A}_{2}} \\
\pi^{* *}=\frac{\gamma \tilde{A}_{1}^{2}}{2 \tilde{A}_{2}}
\end{gathered}
$$

where $\tilde{A}_{1}=R-w_{h} \lambda>0 ; \quad \tilde{A}_{2}=2 R \gamma-w_{h}^{2} \theta^{2} \lambda^{2}>0$. 
Proposition 2: Given a finite $G$, if the wage gap between these two countries is high enough, the monopoly firm will undertake OFDI.

Proof: Let net benefits from OFDI to be denoted by $f(\lambda)=\pi^{* *}-\pi^{*}-G$. Since it is assumed that the only benefits from OFDI is the labor cost savings, the upper bound of the benefits from OFDI is $\pi^{* *}-\left.\pi^{*}\right|_{\lambda=0}=\frac{w_{h}\left(2 \gamma A_{1}+R A_{3}\right)}{4 A_{2}}$. Therefore, the firm will undertake OFDI only if $G<\frac{w_{h}\left(2 \gamma A_{1}+R A_{3}\right)}{4 A_{2}}$. Assume that $\left.f(\lambda)\right|_{\lambda=0}>0$, which implies that if the sunk costs of $\mathrm{G}$ is not too large and there is no variables costs to produce abroad, the firm will undertake OFDI. Note that $\left.f(\lambda)\right|_{\lambda=1}=-G<0$, which implies that if the wage rates (in terms of the same currency) of these two countries are equal $(\lambda=1)$, then the firm will not undertake OFDI. In addition, $\frac{\partial f(\lambda)}{\partial \lambda}=-\frac{R w_{h} \gamma \tilde{A}_{1} \tilde{A}_{3}}{\tilde{A}_{2}^{2}}<0$, where $\tilde{A}_{3}=2 \gamma-w_{h} \theta^{2} \lambda>0$. By Mean Value Theorem, there exists $\lambda^{*}$ such that $f\left(\lambda^{*}\right)=0$. That is, there exist a $\lambda^{*}$ such that when $\lambda<\lambda^{*}, f(\lambda)>0$.

Note that $\lambda=R\left(w_{f} / w_{h}\right), 0 \leq \lambda \leq 1$. Hence, the above result implies that if the relative wage in the foreign country $\left(w_{f} / w_{h}\right)$ is low enough, or the exchange rate of the home currency $(R)$ is low enough, the monopoly firm will undertake OFDI.

This proposition indicates that if the relative wage rate in the foreign country is low enough, or the exchange rate of home currency is low enough, the monopoly firm will undertake OFDI to take advantage of its lower labor costs. The economic intuition for the results in Proposition 2 is clear. Since we assume that the overseas investment is driven by the labor cost savings, if the wage gap (in terms of the same currency) is large enough, it will be worthwhile to incur sunk costs $\mathrm{G}$ to take advantage of the lower labor cost in the foreign country. The decrease in the exchange rate (i.e., appreciation of home currency) will widen the wage gap so as to stimulate the firm to undertake OFDI.

From Eqs. (8) and (15), we can derive the threshold for the firm to undertake OFDI, $\lambda^{*}$ :

$$
\lambda^{*}=\frac{R \gamma A_{2}-2 \sqrt{R \gamma\left(\gamma A_{1}^{2}+2 G A_{2}\right)\left(4 G \theta^{2} A_{2}+R A_{3}^{2}\right)}}{w_{h}\left(R \gamma A_{3}+R \gamma \theta^{2} A_{1}+2 G \theta^{2} A_{2}\right)}
$$

Eq. (16) indicates that there are many other factors will affect the firm's decision of OFDI, such as productivity of $\mathrm{R} \& \mathrm{D}(\theta)$, cost effectiveness of $\mathrm{R} \& \mathrm{D}(\gamma)$ and so forth.

\section{The Impact of OFDI on Domestic R\&D}

To investigate the impact of OFDI on the investing firm's R\&D spending, we calculate the differences between $I^{*}$ in Eq. (6) and $I^{* *}$ in Eq. (13) as follows: 


$$
I^{* *}-I^{*}=\frac{R w_{h} \theta(1-\lambda)\left(w_{h} \lambda A_{3}-2 \gamma A_{1}\right)}{A_{2} \tilde{A}_{2}}
$$

From Eq. (17), it can be shown that the impact of a firm's OFDI on its R\&D investment is ambiguous, which depends on the wag gap of these two countries, which is summarized in the following proposition 3.

Proposition 3: The OFDI of a monopoly firm will stimulate its R\&D spending if the wage gap between home country and host country is not too large. Otherwise, the OFDI of the firm will depress its R\&D spending.

Proof: From Eq. (17), it is straightforward to obtain the result that if $1>\lambda>\lambda^{* *}$, where $\lambda^{* *}=\frac{2 \gamma A_{1}}{w_{h} A_{3}}$, then $I^{* *}-I^{*}>0$; and if $\lambda<\lambda^{* *}$, then $I^{* *}-I^{*}<0$.

The economic intuition behind the results in Proposition 3 is as follows. On one hand, since the firm faces a lower wage rate after undertaking OFDI, the returns from its R\&D will be lower, thus reducing its incentive to undertake R\&D. This is a substitution effect induced by OFDI, as pointed out by Chen and Yang (2013). On the other hand, a lower wage rate decreases its marginal production cost so as to enhance the firm's optimal output. The increase in its output will reduce the average cost of $\mathrm{R} \& \mathrm{D}$, and thus increasing its optimal $\mathrm{R} \& \mathrm{D}$ spending, which is cost-spreading effect mentioned above. If the wage gap large enough, the substitution effect will dominate the cost-spreading effect. In contrast, if the wage gap is low, the cost-spreading effect will dominate the substation effect. Therefore, the impact of OFDI on R\&D spending is ambiguous.

\section{The Model with Two Identical Firms}

\subsection{The Model}

In this section, we extend our basic model to the setting of a three-stage non-cooperative game with two identical firms in the home country: Firms 1 and 2. Suppose that both firms manufacture a homogeneous good and compete in the foreign market. The firms compete in output as well as R\&D spending. We focus on the case that only one of the firms undertakes OFDI, say Firm 1. In the first stage, Firm 1 determines if it will serve the market via exports or FDI. In the second stage, given the entry mode decision of Firm 1, both firms choose their R\&D spending levels simultaneously. In the third stage, given their R\&D spending levels, both firms choose their output levels simultaneously. Let $I_{i}$ be the level of R\&D undertaken by firm $i$ and let $c_{i}$ denote firm $i$ 's marginal cost $(i=1,2)$. The output levels of the firms are $q_{1}$ and $q_{2}$, respectively. Let $q_{1}+q_{2}=q$.

\section{The Case of Export}

We first consider the case that both firms produce at home and serve the foreign country via exports. The profits of the firms can be written as

$$
\pi_{i}=\left[R p(q)-w_{h}\left(1-\theta I_{i}\right)\right] q_{i}-\gamma I_{i}^{2} / 2, \quad i=1,2
$$

Differentiating $\pi_{i}$ with respect to $q_{i}$, we can obtain the following reaction functions of the firms from the first-order conditions:

$$
\begin{aligned}
& q_{1}=\frac{R-c_{1}-R q_{2}}{2 R} \\
& q_{2}=\frac{R-c_{2}-R q_{1}}{2 R}
\end{aligned}
$$

It is clear from Eqs. (19) and (20), the reaction functions have negative slopes. Hence, the output levels of these two firms are strategic substitutes. Solving Eq. (19) and (20) simultaneously, we obtain the optimal output levels of the firms as follows: 


$$
q_{i}^{*}=\frac{R-2 c_{i}+c_{-i}}{3 R}, \quad i=1,2
$$

It is clear from Eqs. (21) that, $\partial q_{i}^{*} / \partial R>0, i=1,2$, which suggest that depreciation of home currency will stimulate the output levels of the firms.

Substituting Eqs. (21) and (22) into the profit functions, we then solve the second-stage problem by differentiating the profit functions with respect to $I_{i}$. From the first-order conditions, we can derive the reaction functions for the firms’ R\&D spending as follows:

$$
\begin{aligned}
& I_{1}=\frac{4 \theta w_{h}\left(-R+w_{h}+I_{2} \theta w_{h}\right)}{8 \theta^{2} w_{h}^{2}-9 \gamma R} \\
& I_{2}=\frac{4 \theta w_{h}\left(-R+w_{h}+I_{1} \theta w_{h}\right)}{8 \theta^{2} w_{h}^{2}-9 \gamma R}
\end{aligned}
$$

The denominator of Eq. (22) or (23) is the second-order condition of this maximization problem and it is negative when we assume that this condition holds. Consequently, it is clear that, if the second-order condition holds, the slopes of the reaction functions for the firms' R\&D are also negative, which implies that their R\&D activities are strategic substitutes. Solving Eqs. (22) and (23) simultaneously yields the following optimal R\&D levels:

$$
I_{i}^{*}=\frac{4 w_{h} \theta A_{1}}{B_{2}}, \quad i=1,2
$$

where $B_{2}=9 R \gamma-4 w_{h}^{2} \theta^{2}$. To ensure that the R\&D levels are positive, we assume that $B_{2}>0$.

Substituting Eqs. (24) into Eqs. (21) and (18), we obtain optimal output and profit levels as follows:

$$
\begin{gathered}
q_{i}^{*}=\frac{3 \gamma A_{1}}{B_{2}}, \quad i=1,2 \\
\pi_{i}^{*}=\frac{\gamma A_{1}^{2} B_{3}}{B_{2}^{2}}, \quad i=1,2
\end{gathered}
$$

where $B_{3}=9 R \gamma-8 w_{h}^{2} \theta^{2}$. To ensure that the profit levels are positive, we assume that $B_{3}>0$.

Proposition 4: The optimal R\&D level of the duopoly are positively related to R\&D productivity and negatively related to cost effectiveness of the firms' R\&D activity. However, the relationship between its optimal R\&D level and exchange rate or wage rate is indeterminate.

Proof: Differentiating Eq. (24) with respect to $\theta, \gamma, R$ and $w_{h}$, we have

$$
\begin{gathered}
\frac{\partial I_{i}}{\partial \theta}=\frac{4 w_{h} A_{1} B_{2}}{B_{2}{ }^{2}}>0 \quad, \quad i=1,2 \\
\frac{\partial I_{i}}{\partial \gamma}=-\frac{36 R \theta w_{h} A_{1}}{B_{2}{ }^{2}}<0, \quad i=1,2
\end{gathered}
$$




$$
\begin{gathered}
\frac{\partial I_{i}}{\partial R}=\frac{4 \theta w_{h}^{2}\left(9 \gamma-4 \theta^{2} w_{h}\right)}{B_{2}^{2}}>0 \quad, \quad i=1,2 \\
\frac{\partial I_{i}}{\partial w_{h}}=\frac{4 R \theta\left(4 \theta^{2} w_{h}^{2}+9 \gamma\left(R-2 w_{h}\right)\right)}{B_{2}^{2}}, \quad i=1,2
\end{gathered}
$$

Proposition 5: The optimal output levels of the duopoly firms are positively related to R\&D productivity, the cost effectiveness of the firms' R\&D activity, and exchange rate. However, the optimal output levels and wage rate are negatively related.

Proof: Differentiating Eq. (25) with respect to $\theta, \gamma, R$ and ${ }^{w_{h}}$, we have

$$
\begin{gathered}
\frac{\partial q_{i}}{\partial \theta}=\frac{24 \gamma \theta w_{h}^{2}\left(R-w_{h}\right)}{B_{2}{ }^{2}}>0 \quad, \quad i=1,2 \\
\frac{\partial q_{i}}{\partial R}=\frac{3 \gamma w_{h}\left(9 \gamma-4 \theta^{2} w_{h}\right)}{B_{2}{ }^{2}}>0 \quad i=1,2 \\
\frac{\partial q_{i}}{\partial \gamma}=-\frac{12 \theta^{2} w_{h}^{2}\left(R-w_{h}\right)}{B_{2}{ }^{2}<0 \quad, \quad i=1,2} \\
\frac{\partial q_{i}}{\partial w_{h}}=-\frac{3 \gamma\left(9 \gamma R-8 R \theta^{2} w_{h}+4 \theta^{2} w_{h}^{2}\right)}{B_{2}{ }^{2}}<0 \quad, \quad i=1,2
\end{gathered}
$$

While the economic intuition behind the results in Proposition 4 is similar the case of monopoly, the economic rationale behind the results in Proposition 5 is straightforward. The increase in the firms' R\&D productivity, the cost effectiveness of R\&D spending and exchange rate will increase the firm's incentive to undertake $R \& D$ to reduce their marginal costs, and thus stimulating the firms' optimal output. The increase in exchange rate (depreciation of the home currency) can also enhance the marginal revenue of the firm's output so as to simulate their output levels. In contrast, an increase in wage rate will raise the marginal costs of the firms, and thus reducing their optimal output levels.

\section{The Case of OFDI}

Suppose that Firm 1 determines to undertake OFDI. Its profit can be written as

$$
\pi_{1}=\left[R p(q)-R w_{f}\left(1-\theta I_{1}\right)\right] q_{1}-\gamma I_{1}^{2} / 2-G
$$

Appling similar reasoning as the case of export, we can solve for the equilibrium optimal output and R\&D levels for both firms as follows:

$$
\begin{gathered}
q_{1}^{* *}=\frac{3 \gamma\left[\tilde{A}_{1} B_{6}+3 R \gamma w_{h}(1-\lambda)\right]}{2 B_{4} \tilde{B}_{6}+3 R \gamma B_{6}} \\
q_{2}^{* *}=\frac{3 \gamma\left[A_{1} \tilde{B}_{6}-3 R \gamma w_{h}(1-\lambda)\right]}{2 B_{4} \tilde{B}_{6}+3 R \gamma B_{6}} \\
I_{1}^{* *}=\frac{4 w_{h} \theta \lambda}{3 \gamma} q_{1}^{* *}
\end{gathered}
$$




$$
I_{2}^{* *}=\frac{4 w_{h} \theta}{3 \gamma} q_{2}^{* *}
$$

where $B_{4}=3 R \gamma-2 w_{h}^{2} \theta^{2}>0 ; \quad B_{6}=3 R \gamma-4 w_{h}^{2} \theta^{2} ; \quad \tilde{B}_{6}=3 R \gamma-4 w_{h}^{2} \theta^{2} \lambda^{2}$. To ensure that equilibrium output levels are positive, we assume that $\tilde{B}_{6} \geq B_{6}>0$. The profit level of the Firm 1 can be calculated as

$$
\pi_{1}^{* *}=\frac{\tilde{B}_{3}}{9 \gamma}\left(q_{1}^{* *}\right)^{2}-G
$$

where $\tilde{B}_{3}=9 \bar{R} \gamma-8 w_{h}^{2} \theta^{2} \lambda^{2}>0$

\section{The Choice of Entry Mode}

Similarly to the case of monopoly, we try to derive a threshold value of the wag gap, $\lambda_{1}^{*}$, such that if $\lambda<\lambda_{1}^{*}$, one of the duopoly firms will undertake OFDI, as shown in Proposition 2. However, because $\lambda_{1}^{*}$ is too complicated for us to obtain an explicit result. Therefore, we will resort to numerical simulation in the following subsection to examine if the result in Proposition 2 still holds in the case of duopoly.

\section{The Impact of OFDI on Domestic R\&D}

From Eqs. (24), (38) and (39), we can calculate the impacts of Firm's 1 OFDI on its R\&D spending of both firms as follows:

$$
\begin{aligned}
& I_{1}^{* *}-I_{1}^{*}=\frac{4 R w_{h} \theta(1-\lambda)\left(2 w_{h} \lambda B_{4} B_{5}-3 \gamma A_{1} B_{3}\right)}{B_{2}\left(2 B_{4} \tilde{B}_{6}+3 R \gamma B_{6}\right)} \\
& I_{2}^{* *}-I_{2}^{*}=\frac{12 R \gamma w_{h}^{2} \theta(1-\lambda)\left(4 w_{h} \theta^{2} \lambda A_{1}-R B_{5}\right)}{B_{2}\left(2 B_{4} \tilde{B}_{6}+3 R \gamma B_{6}\right)}
\end{aligned}
$$

where $B_{5}=9 \gamma-4 w_{h} \theta^{2}>0$. (Note 8$)$

Similar to the case of monopoly, we can show that the relationship between a firm's OFDI and its R\&D spending or the R\&D spending of the other firm is indeterminate under the setting of duopoly. The results are summarized in the following propositions.

Proposition 6: If Firm 1 only undertakes OFDI, the OFDI will stimulate its R\&D spending if the wage gap between home country and host country is not too large. Otherwise, the OFDI of the firm will depress its R\&D spending.

Proof: From the Eq. (41), it is straightforward to show that if $1>\lambda>\lambda_{1}^{* *}$, where $\lambda_{1}^{* *}=3 \gamma A_{1} B_{3} / 2 w_{h} B_{4} B_{5}$, then

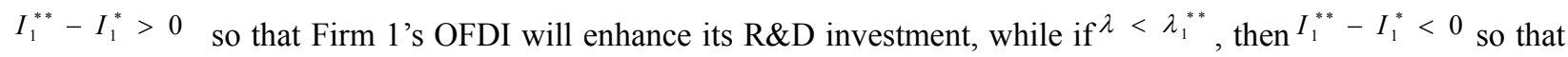
the firm's OFDI will depress its R\&D investment.

Proposition 7: If Firm 1 only undertakes OFDI, the OFDI will stimulate the R\&D spending of Firm 2, if the wage gap between home country and host country is not too large. Otherwise, the OFDI of the firm will depress its R\&D spending.

Proof: From the Eq. (42), it is straightforward to show that if $1>\lambda>\lambda_{2}^{* *}, \lambda_{2}^{* *}=\bar{R} B_{5} / 4 w_{h} \theta^{2} A_{1}$, Firm 1 's OFDI will enhance firm 2's R\&D investment, while if $\lambda<\lambda_{2}^{* *}$, the firm's OFDI will depress firm 2 's R\&D investment.

Propositions 6 and 7 indicate that the OFDI of Firm 1 will have an ambiguous impact of the R\&D spending of both 
firms, which depend on the wage gap between the home country and host country. However, under the assumptions of our analytical framework, the output and R\&D strategies of these two firms are strategic substitutes, consequently, if Firm 1's OFDI enhance its R\&D spending, the R\&D spending of Firm 2 will decrease; and vice versa. Therefore, we can summarize these results in the following proposition.

Proposition 8. If $\lambda<\lambda_{1}^{*}<\lambda_{2}^{* *}$ or $\lambda<\lambda_{2}^{* *}<\lambda_{1}^{*}$, then Firm 1's OFDI will depress Firm 2's R\&D spending. In contrast, if $\lambda_{2}^{* *}<\lambda<\lambda_{1}^{*}$, then Firm 1's OFDI will enhance Firm 2's R\&D spending.

\section{The Model with Two Heterogeneous Firms}

In this section, we further extend our basic model to the setting of a three-stage non-cooperative game with two heterogeneous firms. Suppose that the firms compete in output as well as R\&D spending. In addition, both firms might differ in production productivity $(v)$ and/or cost effectiveness of $R \& D^{(1 / \gamma)}$. We are interested in the following questions: Facing an increase in labor costs or appreciation of home currency, which firm will choose "moving-out strategy", i.e., to relocate its production abroad, and which firm will choose "moving-up strategy", i.e., to stay at home and increase its R\&D spending? In addition, if one of the firm moves out, how the R\&D of the investing firm and the other firm will be affected? Since it is too complex to derive analytical solutions for this setting, we have to resort to numerical simulation in the following analysis. The baseline setting for the parameters of the model are: ${ }^{w_{h}}=1, \lambda=0.85, \gamma=1, \theta=1, R=1, v=5, \alpha=35, G=25$.

\section{The Choice of Entry Mode}

To investigate the relationship between production productivity and entry mode choice, we assume that the production productivities of these two firm have a proportionate relationship: $v_{1}=\delta v_{2}, \delta>0$. If $\delta>1$, it implies that Firm 2 has higher production productivity, and vice versa. Figure 1 indicates that if $\delta>1$, then it is more profitable for the firm with lower production productivity, i.e., Firm 1, to undertake OFDI, which suggests that if the host country has cost advantage, the less productive firm will locate abroad whereas the more productive one produce at home. This result is consistent with the prediction of Head and Ries (2003).

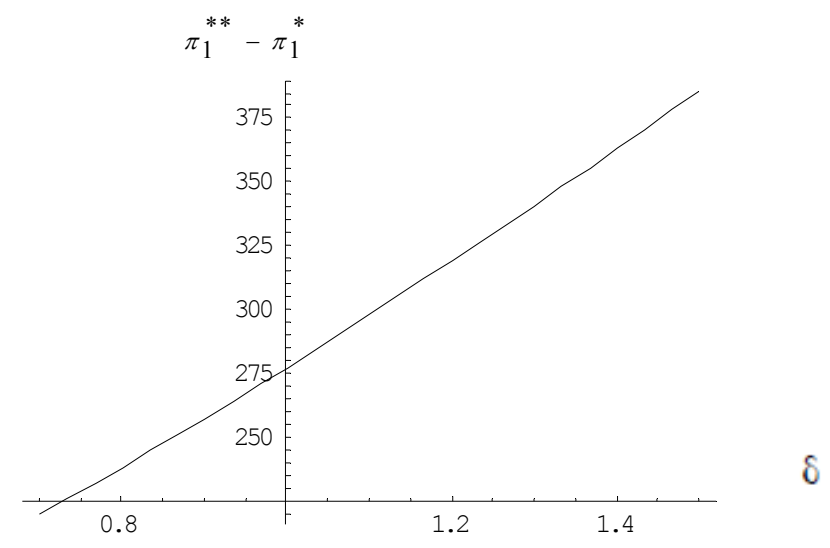

Figure 1. Production productivity and profitability of OFDI

To investigate the relationship between cost effectiveness of R\&D and entry mode choice, we assume that the cost effectiveness of R\&D of these two firm have a proportionate relationship: $\gamma_{1}=\beta \gamma_{2}, \beta>0$. If $\beta>1$, it implies that Firm 2 has higher productivity in undertaking R\&D activity; and vice versa. Figure 2 indicates that if $\beta>1$, then it is more profitable for the firm with lower productive in R\&D activity, i.e., Firm 1, to undertake OFDI, which suggests that if the host country has cost advantage, the less productive firms in R\&D activity might choose 
"moving-out" strategy to take advantage of lower labor costs whereas the more productive one produces at home.

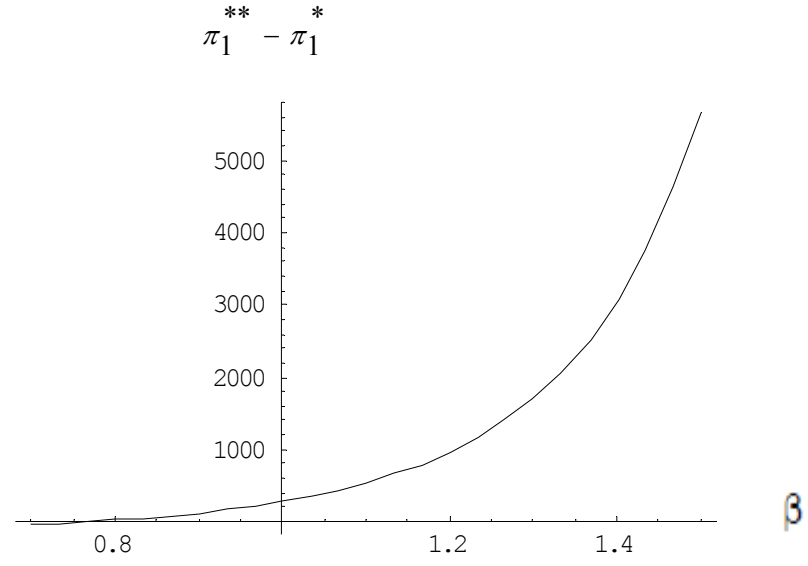

Figure 2. Cost effectiveness of R\&D and profitability of OFDI

\section{The Impact of OFDI on Domestic R\&D}

As for the impact of OFDI on R\&D spending, Proposition 8 indicates that the results will depend on the wage gap between these two countries, and the OFDI have opposite effects on the R\&D of the investing firm and the R\&D of the other firm. However, Eqs. (41) and (42) indicate that other firms characteristics, such as production productivity and cost effectiveness of R\&D activity, will also have some influence on these results. In the following we use numerical simulation to illustrate several possible situations.

Figures 3 and 4 show that when the wage gap between these two counties is large enough $(\lambda=0.5)$, the OFDI of a firm (Firm 1) will depress its $R \& D$ spending and enhance the $R \& D$ spending of the other firm regardless of the relative magnitude of production productivities $(\delta)$. In contrast, Figures 5 and 6 illustrate that when the wage gap between these two counties is low enough $(\lambda=0.85)$, the OFDI of a firm will stimulate its R\&D spending and depress the R\&D spending of the other firm regardless of the relative magnitude of production productivities. These results are consistent with the prediction of Proposition 8.

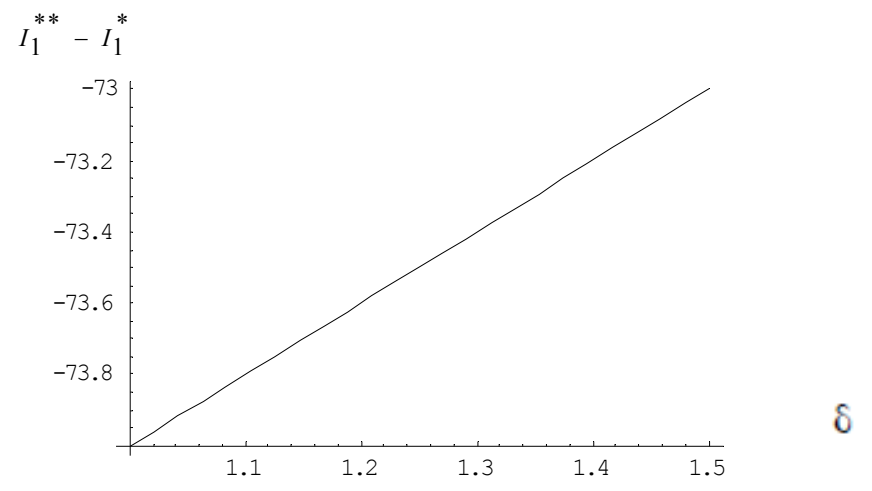

Figure 3. Production productivity and R\&D of OFDI firm $(\lambda=0.5)$ 


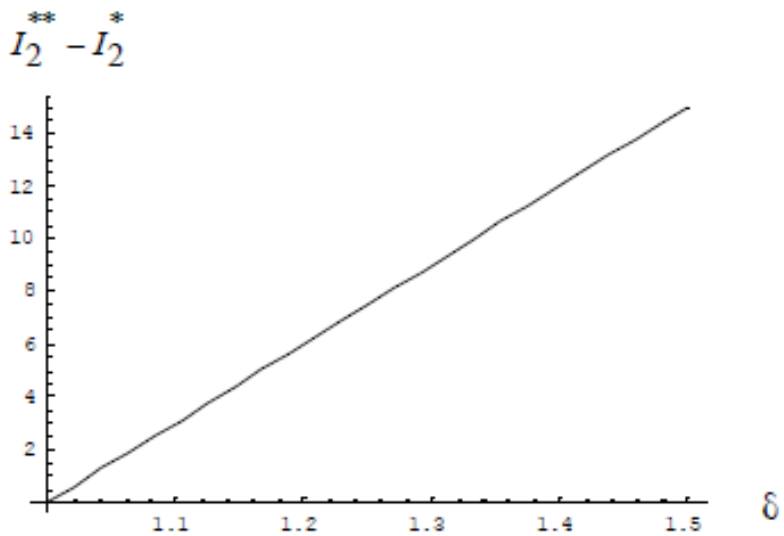

Figure 4. Production productivity and R\&D of non-OFDI firm $(\lambda=0.5)$

$$
I_{1}^{* *}-I_{1}^{*}
$$

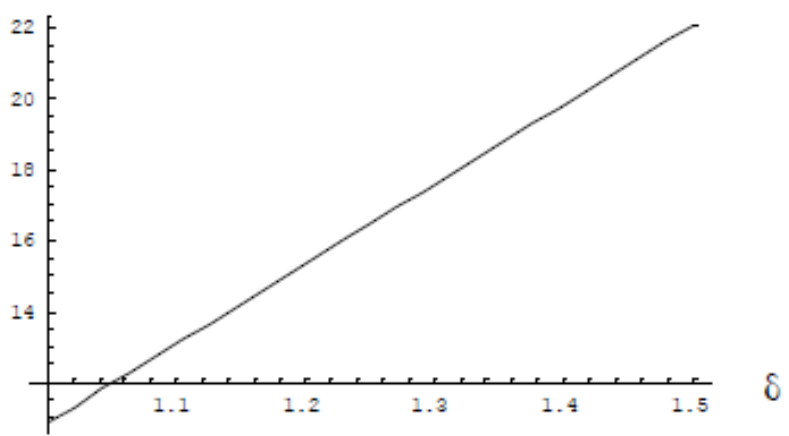

Figure 5. Production productivity and R\&D of OFDI firm $(\lambda=0.85)$

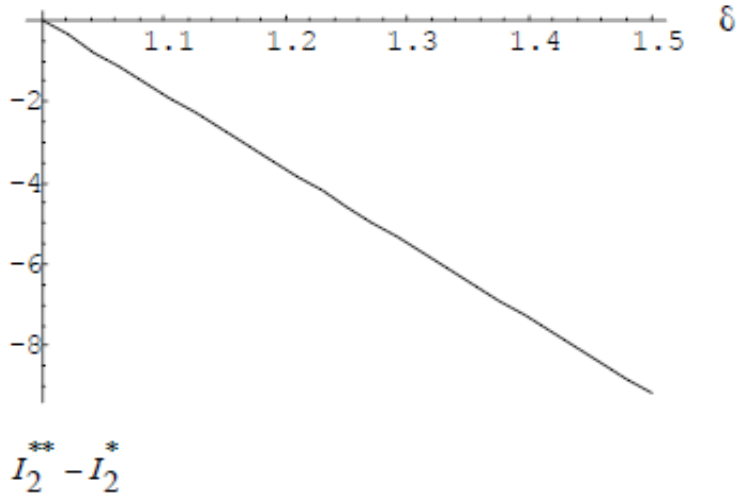

Figure 6. Production productivity and R\&D of non-OFDI firm ( $\lambda=0.85$ )

As for the case in which the firms differ in cost effectiveness in R\&D activity, Figures 7 and 8 show that when the wage gap between these two counties is large enough $(\lambda=0.5)$, the OFDI of a firm (Firm 1$)$ will depress its R\&D spending and enhance the R\&D spending of the other firm regardless of the relative magnitude of cost effectiveness in $\operatorname{R} \& D$ activity $(\beta)$. In contrast, Figures 9 and 10 indicate that when the wage gap between these two counties is low enough ( $\lambda=0.7$ ), the OFDI of a firm might stimulate its R\&D spending or depress on its R\&D spending, depending on the differences in cost effectiveness in R\&D activity. If the differences in cost effectiveness in R\&D activity are large enough, Firm 1's OFDI will depress its R\&D activity, but stimulate Firm 2's R\&D spending. On the 
contrary, if the differences in cost effectiveness in R\&D activity are small, Firm 1's OFDI will stimulate its R\&D activity, but depress Firm 2's R\&D. In other words, if the differences in wage rates between these two counties are not too large and the investing firm's relative productivity in R\&D activity is not too low, the OFDI will enhance the investing firm's R\&D. These results can be attributed to the fact that there are two opposing effects induced by OFDI. If the relative cost effectiveness of the investing firm is not too high (i.e. $\beta$ is large), it is more likely that the negative "substitution effect" will dominate the positive "cost-spreading effect" so as to reduce the incentive of the investing firm's R\&D spending.

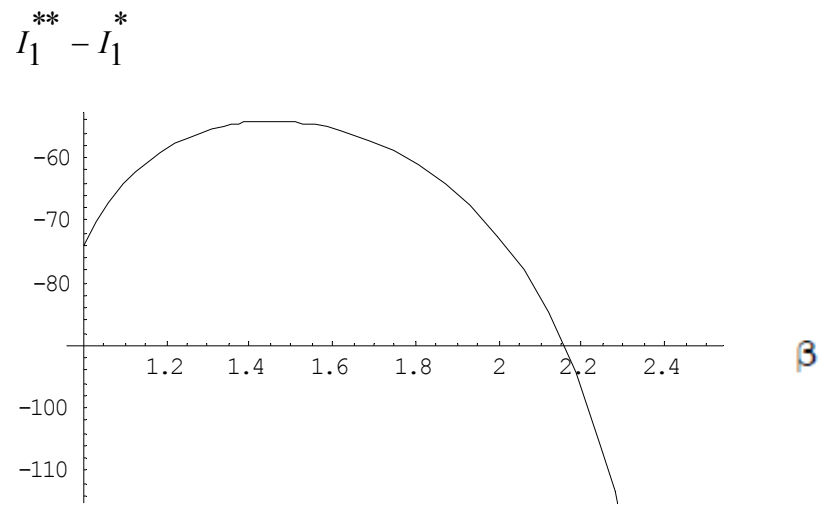

Figure 7. Cost effectiveness of R\&D and R\&D of OFDI firm ( $\lambda=0.5$ )

$$
I_{2}^{* *}-I_{2}^{*}
$$

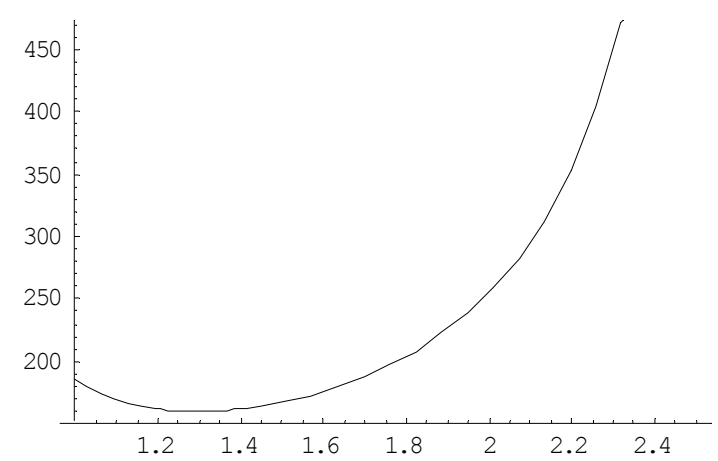

Figure 8. Cost effectiveness of R\&D and R\&D of non-OFDI firm ( $\lambda=0.5)$

$$
I_{2}^{* *}-I_{2}^{*}
$$

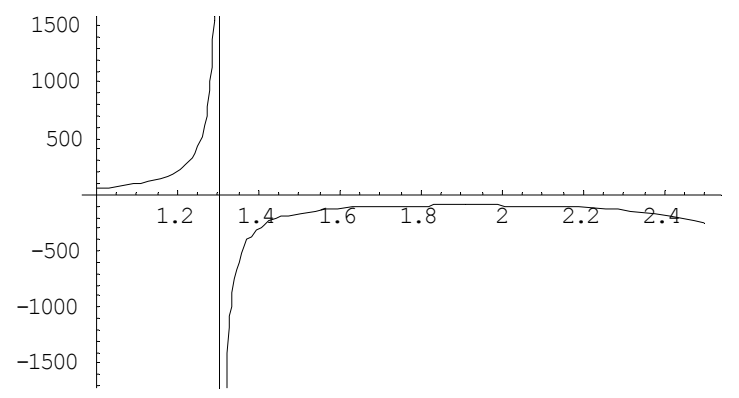

Figure 9. Cost effectiveness of R\&D and R\&D of OFDI firm ( $\lambda=0.7$ ) 


$$
I_{1}^{* *}-I_{1}^{*}
$$

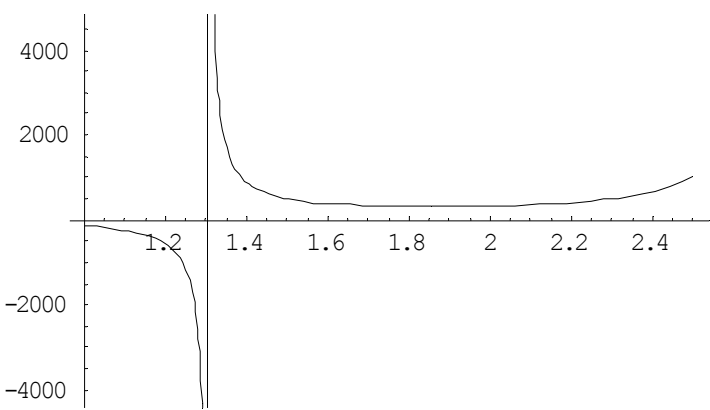

Figure 10. Cost effectiveness of R\&D and R\&D of non-OFDI firm ( $\lambda=0.7$ )

\section{Conclusion}

This paper develops a game-theoretical model to investigate heterogeneous firms' entry mode choice of international expansion. The distinct feature of this paper is that exchange rate, R\&D competition, and intra-industry firm heterogeneity are incorporated into the theoretical framework. The possible impact of a firm's outward foreign direct investment (OFDI) on its R\&D spending and other non-OFDI firms' R\&D spending is also examined.

Our analytical results indicate that, if the host country has cost advantage, when facing rising domestic labor costs or appreciation of home currency, a firm with lower productivity in production or R\&D activity will choose OFDI, whereas the firms with higher productivity will stay at home and export. These results are consistent with the prediction of Head and Ries (2003).

In addition, our results demonstrate that the impact of OFDI on R\&D spending is ambiguous, depending on firm heterogeneity as well as the wage gap between home country and host country. Specifically, when the wage gap between these two counties is large enough, the OFDI of a firm will depress its R\&D spending and enhance the R\&D spending of the non-OFDI firm. However, when the wage gap is low enough, the OFDI of a firm might stimulate its R\&D spending, unless its productivity in R\&D is too low. These results suggest that OFDI and domestic R\&D could be complements or substitutes, depending on the wage gap. This is an important empirical issue, and further research seems warranted.

\section{References}

Bernard, A.B., \& J.B. Jensen. (1995). Exporters, jobs and wages in US manufacturing: 1976-1987. Brookings Papers on Economic Activity, 67-119. http://dx.doi.org/10.2307/2534772

Bernard, A.B., \& J.B. Jensen. (1999). Exceptional exporter performance: cause, effect, or both?, Journal of International Economics, 47, 1-25. http://dx.doi.org/10.2307/2534772

Bernard, A.B., J. Eaton, J.B. Jensen, \& S. Kortum. (2003). Plants and productivity in international trade, American Economic Review, 93, 1268-11290. http://dx.doi.org/10.1257/000282803769206296

Bernard, A.B., J.B. Jensen, S.J. Redding, \& P.K. Schott. (2012). The empirics of firm heterogeneity and international trade. CES Discussion paper 12-18, U.S. Census Bureau.

Caves, R.E. (1996). Multinational Enterprise and Economic Analysis. Cambridge: Cambridge University Press.

Chen, C.L., \& F.S. Hsu. (2003). Defensive foreign direct investment and endogenous R\&D. Academia Economics Papers, 31, 577-603. (in Chinese with English summary)

Chen, K.M., H.H. Rau, \& C.C. Lin. (2006). The impact of exchange rate movements on foreign direct investment: market-oriented versus cost-oriented. The Developing Economies, 44, 269-287. http://dx.doi.org/10.1111/j.1746-1049.2006.00017.x

Chen, K.M, \& S. F. Yang. (2013). Impact of outward foreign investment on domestic R\&D activity: evidence from Taiwan's multinational enterprises in low-wage countries. Asian Economic Journal, 27, 17-38. http://dx.doi.org/10.1111/asej.12000

Cohen, W. M., \& S. Klepper. (1996). A reprise of size and R\&D. Economic Journal, 106, $925-951$. 
http://dx.doi.org/10.2307/2235365

Dunning, J.H. (1977). Trade, location of economic activity and the MNE: a search for an eclectic approach. In Ohlin, Bertil, Hesselborn, Per Ove, Wijkman, \& Per Magnus (Eds.), International Allocation of Economic Activity. The Macmillan Press, London.

Greenway, D., \& R. Kneller. (2007). Firm heterogeneity, exporting and foreign direct investment. Economic Journal, 117, F134-F116. http://dx.doi.org/10.1111/j.1468-0297.2007.02018.x

Head, K., \& J. Ries. (2003). Heterogeneity and the FDI versus export decision of Japanese manufactures. Japanese and International Economies, 17, 448-467.

Helpman, E., M.J. Melitz, \& S.R. Yeaple. (2004). Export versus FDI with heterogeneous firms. American Economic Review, 94, 300-316. http://dx.doi.org/10.1257/000282804322970814

Hsu, J. (2011). How do innovation and exchange changes affect firms' mode of foreign expansion? Journal of International Trade \& Economic Development, 20, 429-447. http://dx.doi.org/10.1080/09638190903003044

Lin, C.C., K.M. Chen, \& H.H. Rau. (2010). The impact of exchange rate movements on the timing of foreign direct investment: market-seeking versus export-substituting. Review of Development Economics, 14, 466-486. http://dx.doi.org/10.1111/j.1467-9361.2010.00565.x

Lu, C.H. (2007). Moving-up or moving-out? A unified theory of R\&D, FDI, and trade. Journal of International Economics, 71, 324-343. http://dx.doi.org/10.1016/j.jinteco.2006.04.003

Melitz, M.J. (2003). The impact of trade on intra-industry reallocations and aggregate industry productivity. Econometrica, 71, 1695-1725. http://dx.doi.org/10.1111/1468-0262.00467

Petit, M.L., \& F. Sanna-Randaccio. (1998). Technological innovation and international expansion: A two-way link? Journal of Economics, 68, 1-26. http://dx.doi.org/10.1007/BF01237461

Petit, M.L., \& F. Sanna-Randaccio. (2000), Endogenous R\&D and foreign direct investment in international oligopolies. International Journal of Industrial Organization, 18, 339-367. http://dx.doi.org/10.1016/S0167-7187(98)00028-9

Tsai, Yi-Cheng, \& Jiunn-Rong Chiou. (2007). Foreign direct investment and research and development. Academia Economics Papers, 35, 53-82. (in Chinese with English summary)

\section{Notes}

Note 1. See, for instance, Greenway and Knetter (2007), and Bernard, et al. (2012) for recent surveys about this new literature.

Note 2. See Chen, et al. (2006) and Lin, et. al. (2010) among others for recent research about the impact of exchange rate movements on OFDI both theoretically and empirically.

Note 3. See Greenway and Kneeter ( 2007), p. F151.

Note 4. The second-order condition, $\partial^{2} \pi_{h} / \partial q^{2}=-2 R<0$, holds.

Note 5. The second-order condition, $\partial^{2} \pi / \partial I^{2}=-A_{2} / 2 R<0$, holds.

Note 6. $\partial q^{*} / \partial R=\frac{\gamma w_{h}\left(2 \gamma-w_{h} \theta^{2}\right)}{\left(w_{h}^{2} \theta^{2}-2 R \gamma\right)^{2}}>0$.

Note 7. It is clear that the second-order conditions for the case also hold.

Note 8 . This condition ensures that the marginal costs of the firms are positive, i.e., $w_{h}\left(1-\theta I_{1}^{*}\right)>0$. 